\title{
ĐÁNH GIÁ KẾT QUẢ PHẪU THUÂT NỘI SOI THOÁT VỊ BẸN Ở TRẺ EM CÓ SỬ DƯNG KIM XUYỀ QUA DA TỰ CHẾ
}

\author{
Nguyễn Việt Hoa ${ }^{1}$, Phạm Quang Hùng ${ }^{1,2}$, Vũ Hồng Tuân ${ }^{1,2}$
}

\section{TÓM TẮT}

Mục tiêu: Đánh giá kết quả điều trị nội soi thoát vị bẹn trẻ em có sử dụng kim xuyên da tự chế tại bệnh viện hữu nghị Việt Đức từ tháng 2 đến tháng 7 nằm 2021. Đối tượng và phương pháp nghiên cứu: Nghiên cứu tiền cứu theo dõi dọc không nhóm chứng. 42 bệnh nhi dưới 16 tuổi, không phân biệt giới tính, được chẩn đoán là thoát vị bẹn được phẩu thuật nội soi. Kết quả: Thời gian mổ trung bình của bệnh nhi là 21,55 $\pm 6,38$ phút. Có $30,9 \%$ bệnh nhi phát hiên thoát vị đối bên trong khi mổ. Không ghi nhận tai biến nào trong mổ. Thời gian nằm viện trung bình của bệnh nhi là 1 ngày. Hậu phẫu: $100 \%$ bệnh nhi không có biến chứng. Sau phẫu thuật 3 tháng: không có trường hợp tái phát, vết mổ đẹp, $97,6 \%$ bố mẹ bệnh nhi hài lòng về vết mổ thẩm. Kết luân: Phẫu thuât nội soi thoát vị bẹn ở trẻ em có sử dụng kim xuyển qua da tự chế là môt phương pháp an toàn, hiệu quả.

Tư khóa: Thoát vị bẹn, phẫu thuật nội soi, trẻ em.

\section{SUMMARY}

THE RESULTS OF ENDOSCOPIC TREATMENT OF

\section{INGUINAL HERNIA IN CHILDREN WITH}

HOMEMADE PERCUTANEOUS NEEDLES

Objectives: To evaluate the results of endoscopic treatment of inguinal hernia in children with homemade percutaneous needles. Subjects and methods: 42 pediatric patients under 16 years of age, regardless of gender, diagnosed with inguinal hernia underwent laparoscopic surgery. Results: The average surgical time of pediatric patients was 21.55 \pm 6.38 minutes. $30.9 \%$ of pediatric patients discovered contralateral hernia during surgery. No complications were recorded during surgery. The mean length of hospital stay was 1 day. Postoperation: $100 \%$ of children had stable incision condition. 3 months after surgery: no patient had recurrent inguinal hernia. The incision is beautiful and aesthetic in $97.6 \%$ of pediatric patients. Time of surgery does not depend on gender, age, time of disease detection, side of hernia and location of hernia mass. Conclusion: Laparoscopic inguinal hernia surgery in children with homemade percutaneous needle is a safe and effective method.

Keywords: Inguinal hernia, laparoscopic surgery, children.

\section{I. ĐĂT VẤN ĐỀ}

\section{${ }^{1}$ Bênh viện Việt Đức.}

2Trường đai hoc Y Hà Nôi

Chịu trách nhiệm chính: Nguyễn Việt Hoa

Email: nvhoa96@yahoo.com

Ngày nhân bài: 18.10 .2021

Ngày phản biên khoa hoc: 20.12.2021

Ngày duyệt bài: 28.12.2021
Thoát vị bẹn (TVB) là bệnh lý ngoại khoa phổ biến nhất ở trẻ em, trong đó hình thái lâm sàng hay gặp nhất là TVB gián tiếp do sự tồn tại của ống phúc tinh mạc (OPTM) gây ra ${ }^{1}$. Bênh gặp ở $2 \%$ đến $5 \%$ trẻ sinh đủ tháng, $9 \%$ đến $11 \%$ trẻ sinh non tháng và có thể lên tới $30 \%$ đến $60 \%$ trẻ sinh non tháng nhe cân². Nguyên tắc điều trị TVB ở trẻ em là đóng lại OPTM tại lỗ bẹn sâu. Mổ mở đường ben là phương pháp kinh điển để điều trị TVB ở trẻ em trong nhiêu thập kỷ qua ${ }^{2,3}$. Tuy nhiên, phẫu thuật nội soi (PTNS) ngày càng được sử dung rộng rãi trong điều trị. Phẫu thuât nội soi ra đời có ưu điểm so với mổ mở kinh điển như thẩm mỹ, kiểm tra được ống phúc tinh mạc bên đối diện ${ }^{24,5}$. Tại bệnh viện Hữu nghị Viềt Đức hiện nay, điều trị thoát vị bẹn bằng phấu thuật nội soi có hai kỹ thuật chính PTNS khâu đóng OPTM hoàn toàn trong phúc mạc và PTNS khâu đóng OPTM ngoài phúc mạc với kim xuyên qua da. Trước đây chúng tôi sử dụng bộ kim EndoneedleNeo để thực hiện việc đóng OPTM ngoài phúc mạc, nhưng do giá thành đắt kéo theo chi phí phấu thuật lên cao. Từ năm 2020 chúng tôi sử dụng bộ kim tự chế, bằng cách sử dụng kim lấy ven $16 \mathrm{G}$, chỉ thép buộc răng và chỉ Ethibond dưới sự hố trợ của hệ thổng nội soi để thắt ống phúc tinh mạc tránh làm tổn thương ống dẫn tinh và bó mạch thừng tinh đồng thời kiểm tra OPTM đối bển cùng trong một cuộc phẫu thuật, kỹ thuật này tỏ ra khá ưu điểm bởi thời gian phẫu thuật ngắn, tỷ lệ tái phát thấp, tính thẩm mỹ cao tương đương mà giá thành rẻ. Vì vậy, chúng tôi tiến hành nghiên cứu nhằm muc tiêu: Mồ tả kỹ thuật và đánh giá kêt quả điều trị nội soi thoát vi bẹ tré em có sư dụng kim xuyên da tự chế tại bệnh viện hữu nghị Việt Đức từ tháng 2 đến tháng 7 năm 2021.

\section{II. ĐỐI TƯỢNG VÀ PHƯƠNG PHÁP NGHIÊN CỨU \\ 2.1. Đối tượng nghiên cứu}

- Tiêu chuẩn lựa chọn: Gồm tất cả các bênh nhi dưới 16 tuổi, không phân biệt giới tính, được chẩn đoán là thoát vị bẹn (bao gồm TVB 1 bên, 2 bên) được phẫu thuật nội soi có sử dụng kim lấy ven hỗ trợ, các hồ sơ của bệnh nhi có đầy đủ thông tin cần cho nghiên cứu

- Tiêu chuẩn loại trứ: Bệnh nhân TVB trong mổ được chẩn đoán là TVB trực tiếp, thoát vị đùi, TVB nghẹt, TVB có kèm ẩn tỉnh hoàn cùng bên. 
Bệnh nhân bị TVB trong mổ phát hiện bệnh lý khác cần phẫu thuật (Nang bạch huyết, nang ruột đôi...). Bệnh nhân bị TVB tái phát sau mổ TVB nội soi. Bệnh nhân mất liên lạc, không khám lại.

\subsection{Phương pháp nghiên cứu}

- Thời gian: từ tháng 2/2021 đến đến hết tháng $7 / 2021$.

- Đia điểm: Khoa phẫu thuật Nhi và Trẻ sơ sinh, bệnh viện Hưu Nghị Việt Đức.

- Thiết kế nghiên cứu: Tiến cứu theo dõi dọc không nhóm chứng.

- Cõ̃ mẫu: Chọn mẫu thuận tiện.

- Kỹ thuật:

$\checkmark$ Dụng cụ: Hệ thống nội soi ổ bụng, 1 ống kính 5mm 300, 1 panh 3mm, 2 trocar: 1 trocar $5 \mathrm{~mm}$ cho camera và 1 trocar $3 \mathrm{~mm}$ cho panh. Bộ kim xuyên da tự chế gồm: kim lấy ven luồn cỡ 16G, chỉ thép (chỉ buộc răng), chỉ không tiêu (Ethibond 2/0).

$\checkmark$ Các bước phẫu thuật: Đặt 1 trocar $5 \mathrm{~mm}$ ở vị trí giữa rốn, bơm hơi áp lực $8-12 \mathrm{mmHg}$ tùy theo lứa tuổi. Đưa camera vào quan sát sự tồn tại OPTM từng bên (còn OPTM 1 bên hay 2 bên). Đặt thêm 1 trocar $3 \mathrm{~mm}$ tại vị trí $6 \mathrm{~h}$ trong đường rạch da rốn, cách trocar $5 \mathrm{~mm}$ khoảng $0,5 \mathrm{~mm}$. Trocar này để cho panh $3 \mathrm{~mm}$. Rạch da $1,5 \mathrm{~mm}$ vị trí tương ứng trên lỗ bẹn sâu. Xuyên kim $16 \mathrm{G}$ qua vết rạch da qua cân cơ tới phúc mạc, luồn kim đi ngoài phúc mac tách phúc mạc ra khỏi bó mạch tinh và ống dẩn tinh rồi đâm thủng phúc mạc vào ổ bụng. Bỏ long sắt. Luồn 1 sợi chỉ thép kèm chỉ Ethibond $2 / 0$ qua lòng nhựa vào ổ bụng. Dùng panh $3 \mathrm{~mm}$ kéo ợi chỉ vào ổ bụng một đoạn. Rút long nhựa của kim. Tiếp dùng kim 16G lại đưa qua vị trí cũ, luồn kim dưới phúc mạc theo hướng ngược lại tới vị trí lỗ thủng phúc mạc lần đâu và đưa kim vào trong ổ bụng, rút long sắt, luồn sợi chỉ thép qua lòng kim vào trong ổ bụng, dùng panh $3 \mathrm{~mm}$ đưa chỉ vào chỉ thép, kéo đẩu còn lại của sợi chỉ ra ngoài. Kết quả sau 2 lần trên sới chỉ đã được luồn 1 vòng quanh OPTM tại lỗ bẹn sâu. Phẫu thuật viên buộc chỉ thắt lại lỗ thoát vị bên ngoài ổ bụng. Nếu thấy còn OPTM bên đối diện, ống bên đấy cũng được khâu kín lại tương tự.
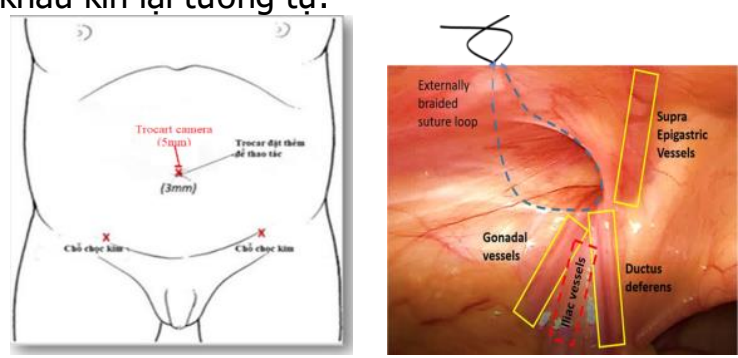

Hình 1: Vị trí đặt Trocar và nguyên tắc PTNS nút thắt ngoài phúc mac.

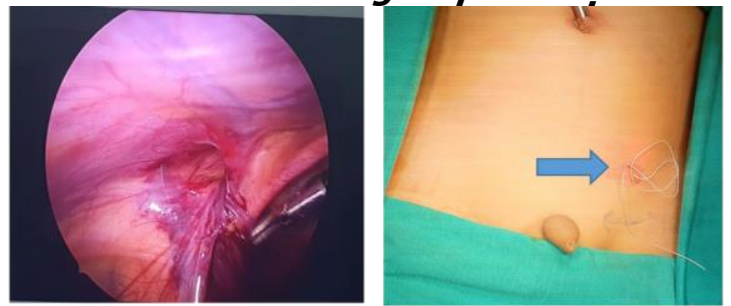

Hình 2: Chỉ sau khi luồn sau phúc mạc và nút thắt bên ngoài (đầu mũi tên)

- Chỉ tiêu nghiên cứu: tuổi bệnh nhân, lâm sàng (TVB 1 bên, 2 bên, bên trái/phải), thời gian phẫu thuật, biến chứng trong mổ (chảy máu, tụ máu, tổn thương bó mạc tinh....). Theo dõi xa sau 3 tháng: tái phát, đánh giá hài lòng của gia đình với vết mổ.

- Xử lý số liệu: Số liêu được nhâp và xử lý bằng phần mềm SPSS 22.0. Tính số trung bình cộng, độ lệch chuẩn, sử dụng test X2, T- test và test Inova để so sánh.

- Đạo đức nghiên cứu: Sự tham gia nghiên cứu đã được đồng thuận của gia đình bệnh nhân. Mọi thông tin về cá nhân được mã hóa và giữ bí mật tuyệt đối. Nghiên cứu đã thông qua hội đồng đạo đức bệnh viện hữu nghị Việt Đức.

\section{KẾT QUẢ NGHIÊN CỨU}

3.1 Đặc điểm lâm sàng, cận lâm sàng bệnh nhi thoát vị bẹn. Trong thời gian nghiên cứu có 42 bệnh nhi được phẫu thuật, tuổi trung bình nhóm bệnh nhi nghiên cứu là $5,1 \pm 2,78$ tuổi. Độ tuổi gặp nhiều nhất là 4 tuổi chiếm 19,0\%. Trong đó độ tuổi $\leq 5$ chiếm $61,9 \%$ Bệnh nhi nam chiếm đa số với 76,2\%. Tỷ lệ nam/nữ là 3,2:1.

Triệu chứng cơ năng thường gặp nhất của bệnh nhi nghiên cứu là bệnh sứ có khối phồng vùng ben/bìu/môi lớn $(85,8 \%)$. Khi khám lâm sàng vùng bẹn, bìu, môi lớn, có $78,6 \%$ số trường hợp nhìn và sờ thấy khối thoát vị, các trường hợp còn lại phát hiện được khối thoát vị khi làm nghiệm pháp tăng áp lực ổ bụng $(21,4 \%)$. Qua chẩn đoán lâm sàng, bệnh nhi nhóm nghiên cứu có tỷ lệ thoát vị bẹn bên phải chiếm đa số (61,9\%). Tỷ lệ bệnh nhi có thoát vị cả 2 bên là 16,7\%.

\subsection{Kết quả điêu trị thoát vị ben}

Bảng 1: Thời gian mổ trung binh

\begin{tabular}{|c|c|c|c|}
\hline $\begin{array}{c}\text { Chấn } \\
\text { đoán nội } \\
\text { soi }\end{array}$ & $\begin{array}{l}\text { Số } \\
\text { BN }\end{array}$ & $\begin{array}{l}\text { Thời gian mố } \\
\text { trung bình } \\
\text { (phút) }\end{array}$ & $\mathbf{p}$ \\
\hline TVB 1 bên & 22 & $18,82 \pm 4,77$ & \multirow{2}{*}{0,12} \\
\hline TVB 2 bên & 20 & $24,55 \pm 6,68$ & \\
\hline Tổng & 42 & $21,55 \pm 6,38$ & \\
\hline
\end{tabular}


Nhận xét: Thời gian mổ trung bình của bệnh nhi là $21,55 \pm 6,38$ phút. Không có sự khác biệt có ý nghĩ thống kê về thời gian mổ trung bình của nhóm TVB 1 bên và 2 bên trên nội soi.

Bảng 2: Chẩn đoán thoát vị bện qua nội soi

\begin{tabular}{|c|c|c|c|c|c|c|}
\hline & \multirow{2}{*}{$\begin{array}{l}\text { Chấn đoán } \\
\text { lâm sàng }\end{array}$} & \multicolumn{2}{|c|}{ Chấn đoán nội soi } & \multirow{2}{*}{$\begin{array}{c}\text { Tỷ lệ TVB } \\
\text { đối bền }\end{array}$} & \multirow{2}{*}{$\mathbf{p}$} \\
\hline & & & Có TVB đối bên & Không có TVB đối bên & & \\
\hline \multirow{3}{*}{$\begin{array}{c}\text { Bên } \\
\text { thoát } \\
\text { vị }\end{array}$} & TVB trái & 9 & 3 & 6 & $33,3 \%$ & \multirow{2}{*}{0,15} \\
\hline & TVB phải & 26 & 9 & 17 & $38,5 \%$ & \\
\hline & Tống & 35 & 12 & 23 & $34,3 \%$ & \\
\hline \multirow{3}{*}{ Giới } & Nam & 32 & 11 & 21 & $34,4 \%$ & \multirow{3}{*}{0,47} \\
\hline & Nữ & 10 & 2 & 8 & $20,0 \%$ & \\
\hline & Tống & 42 & 13 & 29 & $30,9 \%$ & \\
\hline
\end{tabular}

Nhận xét: Bệnh nhân khác nhau về chẩn đoán lẩm sàng và giới có tỷ lệ thoát vị bện đối bên không có sự khác biệt có ý nghĩa thống kê.

Trong phẫu thuật khồng ghi nhận trường hợp nào có các biến chứng: chảy máu, rách phúc mạc, tụ máu dưới phúc mạc, tổn thương ống dấn tinhh, bó mạch thượng vị, mạch chậu hay là chuyển mổ mở.

\section{Bảng 3: Các yếu tố sau phẫu thuật}

\begin{tabular}{|c|c|c|c|}
\hline \multicolumn{2}{|c|}{ Các yếu tố sau phâu thuật } & n & $\%$ \\
\hline \multicolumn{2}{|c|}{$\begin{array}{l}\text { Thời gian nằm viện sau mố trung } \\
\text { bình (ngày) }\end{array}$} & \multicolumn{2}{|c|}{$1,02 \pm 0,15$} \\
\hline \multirow{3}{*}{$\begin{array}{l}\text { Tai biến } \\
\text { sau mổ }\end{array}$} & Tụ máu vùng mố & 0 & 0 \\
\hline & Sưng bìu & 0 & 0 \\
\hline & & 0 & 0 \\
\hline \multicolumn{2}{|c|}{ Tỷ lệ BN phải dùng thuốc giảm đau } & 5 & 9,5 \\
\hline \multirow{2}{*}{$\begin{array}{l}\text { Tình trạng } \\
\text { vết mổ }\end{array}$} & Khô, sạch & 42 & 100 \\
\hline & Nhiềm trùng, chảy dịch & 0 & 0 \\
\hline
\end{tabular}

Nhận xét: Thời gian nằm viện trung bình của bệnh nhi là 1 ngày. Sau phẫu thuật, $100 \%$ bệnh nhi có tình trạng vết mổ ổn định.

\section{BÀN LUẬN}

Mặc dù phẫu thuật mở cổ điển vẫn là tiêu chuẩn vàng cho điêu trị thoát vị bẹn ở trẻ em, phẫu thuật nội soi đang được tiến hành ngày càng nhiêu ở các trung tâm phẫu thuật trên thế giới.

Phương pháp mổ mở đường bẹn được Potts mô tả từ năm $1950^{2}$, trải qua thời gian, phương pháp này đã được hoàn thiên, chuẩn hóa và trở thành phương pháp kinh điển trong điều thoát vị bẹn cho đến tận ngày nay. Tuy nhiên phương pháp này cũng có ưu nhược điểm đã được ghi nhận ${ }^{50}$.Chính những nhược điểm của phương pháp mổ mở đã là động lực cho các phương pháp nội soi ra đời. Trong các kỹ thuật nội soi được áp dụng để điều trị thoát vị ben ở trẻ em, phương pháp phẫu thuật nội soi khẩu đóng ống phúc tinh mạc ngoài phúc mạc với kim xuyên qua da được áp dụng rộng rãi nhất hiện nay ${ }^{3}$.

Uuu điểm của phẫu thuất nội soi: quan sát một cách rõ ràng về giải phẫu (xác định chính xác thoát vị bẹn thông thường hay bất thường, đánh giá được tình trạng thoát vị đặc biệt trong các trường hợp thoát vị bẹn nghẹt); cho biết chính xác loại thoát vị (thoát vị bẹn gián tiếp do tồn tại ống phúc tinh mạc hay thoát vị bẹn trực tiếp, thoát vị đùi); không có các phẫu tích khổng cần thiết do đó nguy cơ tổn thương ống dẫn tinh và bó mạch tinh thấp hơn; phát hiện và sử lý được sự tồn tại của ống phúc tinh mạc bên đối diện mà không cần phải rạch thêm vểt mổ khác; tính thẩm mỹ tốt hơn; dễ thực hiện hơn so với mổ mở trong những trường hợp khó như: thoát vị bẹn nghẹt, thoát vị bẹn tái phát và thoát vị bẹn ở trẻ béo phì ${ }^{4}, 5$. Nhược điểm của phẫu thuật nội soi: Cần có trang thiết bị nội soi và đào tạo phẫu thuật viên do đó giới hạn các trung tâm có thể tiến hành được; bệnh nhân cần phải gây mê nội khí quản; thường dùng chỉ không tiêu khâu đóng ống phúc tinh mạc; khó thực hiện trong trường hợp kèm tinh hoàn ẩn; thủ thuật có thể khó thực hiện hơn ở trẻ nhỏ với quai ruột chướng không gian trong ổ bung hẹp ${ }^{4,6}$.

Trong nghiên cứu, kết quả bảng 1 cho thấy, thời gian phẫu thuật trung bình là $21,55 \pm 6,38$ phút. Không có sự khác biệt có ý nghĩa thống kê về thời gian ổ trung bình của nhóm TVB 1 bên và 2 bên trên nội soi. Thời gian mổ trung bình của chúng tôi có tương đồng với nghiên cứu của tác giả Montupet ${ }^{7}$ là từ 15-24 phút, theo ông nhận thấy thời gian phẫu thuật giảm dần theo kinh nghiệm. Nghiên cứu của Takehara cũng cho thấy: thời gian phẫu thuật đóng ổ bunng qua da ngoài phúc mạc tương đương với thời gian cần thiết cho một ca mổ mở thông thường. Đối với sửa chữa thoát vị một bên, thời gian mổ nội soi là 15 đến 20 phút ở nam và 10 đến 15 phút ở nữ. Thời gian mổ cho khối thoát vị hai bên là 20 đến 25 phút ở nam và 15 đến 20 phút ở nữ. Tác giả giải thích: sự khác biệt về thời gian giữa trẻ em trai và trẻ em gái đến từ việc phẫu tích tỉ mỉ thừng tinh khỏi phúc mạc. Do tiếp xúc chă̆t chẽ giữa thừng tinh và phúc mạc, nên tách các cấu trúc này trước bằng đốt điện và dụng cụ kẹp, mặc dù đối với những phẫu thuật viên đã quen 
với phẫu thuật nội soi, bước này có thể được rút ngắn, kết quả là giảm được 4 phút cho một lần mổ ở 1 bên ${ }^{8}$. Bên cạnh đó, trong 42 bệnh nhi nghiên cứu, chúng tôi phát hiện được 30,9\% trường hợp thoát vị ben bên đối diên chưa biểu hiện lâm sàng (Bảng 2). Đây cũng là một ưu điểm của phương pháp mổ nội soi so với mổ mở. Phát hiện thoát vị bẹn đối bển, phẫu thuật viên sẽ xử trí trước khi có thoát vị ben thực sự cho bệnh nhi. Tuy nhiên không có sự khác biệt về tỷ lệ TVB đối bên ở bệnh nhân khác nhau về chẩn đoán lâm sàng và giới.

Trong phẫu thuật, chúng tôi không ghi nhận trường hợp nào xảy ra tai biến như chảy máu, tổn thương ống dẫn tinh, chuyển mổ mở. Mặc dù chưa ghi nhận nhưng không thể khẳng định là không có, vì theo nhiêu tác giả nhận định rằng: có những tổn thương rất khó nhận biết trong khi mổ ${ }^{9}$. Điều này dễ hiểu vì tổn thương các mạch máu lớn là không ghi nhận tuy nhiên hệ thổng mạch máu từ ổ bụng xuống vùng bìu dày đặc do vậy vẫn có thể tổn thương các mạch nhỏ (gây tụ máu nhỏ ngoài phúc mạc, và nhiều trường hợp trong các hồ sơ bệnh án không mô tả cụ thể tai biến này). Tuy nhiên trong trường hợp này chỉ cần điêu trị bảo tồn. Vì vậy để hạn chế các thương tổn này, cần làm theo quan điểm là phải nắm vững giải phẫu vùng ben và thao tác thật tỉ mỉ, cẩn thâan từng chi tiết, từng thì trong khi mổ.

Thời gian nằm viện sau mổ trung bình là 1,02 $\pm 0,15$ ngày. Chúng tôi không phát hiện có biến chứng nào sau mổ. Chỉ có 4 bệnh nhần $(9,5 \%)$ phải dùng thuốc giảm đau sau mổ (Bảng 3 ). Viêc đánh giá thời gian phục hồi sớm sau mổ khác nhau tùy theo từng tác giả, phần lớn các tác giả đồng tình cách tính thời gian phục hồi sinh hoạt sớm sau mổ là từ khi mổ xong cho đến khi bệnh nhi đứng dậy được, tự tiểu, tự làm một số công việc, được xác định bẳng cách quan sát trực tiếp, hỏi người nuôi, hỏi điêu dưỡng hoặc hỏi trực tiếp bênh nhi (trẻ lớn). Nghiên cứu của tác giả Tin Čohadžić cũng kết luận rằng thời gian nằm trung bình tại bệnh viện là 24 giờ. Dù vậy đa số quan điểm của các phẫu thuật viên đều cho rằng điều trị thoát vị bẹn nội soi có thời gian nằm viện ngắn hơn so với điều trị thoát vị bẹn bằng mổ mở. Điều này được giải thích bằng cách phẫu thuật nội soi phẫu tích nhe nhàng hơn, ít đau hơn sau mổ cũng như thời gian phục hồi sinh hoạt cá nhân sớm hơn nên bệnh nhân có thể xuất viện sớm hơn so với mổ mở. Trong nghiên cứu thời gian nằm viện trung bình của chúng tôi trên 24 giờ do phẫu thuât viên chủ động lưu lại bệnh nhân để theo dõi các biến chứng sớm sau mổ không chỉ của phẫu thuật (chảy máu, nhiễm trùng vết mổ) mà còn là vấn đề của gây mê nội khí quản có tê cùng cụt (bí đái, mệt mỏi ...).

Về biến chứng sau mổ, tuy nghiên cứu của chúng tôi không có ghi nhận trường hợp nào nhưng trong nghiên cứu của Dariusz Patkowski có 4 trường hợp biến chứng sau mổ: một trường hợp dính hồi tràng với thắt ruột và thoát vị tái phát ở 3 bé trai, một trường hợp được mổ lại bằng khâu vòng trong qua da. Chúng tôi cũng không gặp các biến chứng sau mổ như mổ thoát vị bẹn ở người lớn mà Nguyễn Văn Liễu đã nêu ra như bí tiểu sau mổ $(17,9 \%)$, phải mổ lại do tụ máu vùng bìu $(1,06 \%)$, tỉ lệ sưng bìu và tinh hoàn sau mổ cũng thấp hơn nhiêu $(2,2 \%$ so với $8,5 \%$ ). Điều này có thể do mổ chữa thoát vị bẹn trẻ em không phải phẫu tích nhiều, và cũng không cần phục hồi thành bụng như người lớn. Trong nghiên cứu của chúng tôi, tất cả 42 bệnh nhi đều có tình trạng vết mổ khô, sạch, không bị nhiễm trùng (Bảng 5). Ở nhóm mổ mở, ngoài khâu khép lỗ bẹn trong, các mũi khâu đóng cân cơ chéo bụng ngoài gây căng đau sau mổ. Hiện nay, các phẩu thuật làm căng đường khâu như Bassini, McVay, Shouldice... ở người lớn đã dần bị loại bỏ ở trẻ con vì không cần thiết, không hợp với sinh lý giải phẫu vùng bẹn do phải khâu kéo 2 lớp xa nhau và không cùng nằm trong một mặt phẳng lại với nhau làm căng đường khâu, hậu quả là đau nhiều sau mổ và thời gian phục hồi sinh hoạt kéo dài, làm tăng nhu câu dùng thuốc giảm đau sau mổ 5 . Tuy nhiên với cõ mẫu còn nhỏ va thời gian theo dõi chưa dài, chưa đánh giá được các biến chứng về lâu dài của phẫu thuật nội soi TVB cho sự phát triển của tinh hoàn. Chúng tôi chắc chắn sẽ có những nghiên cứu trong tương lai về các khía cạnh này của phẫu thuật.

\section{KẾT LUẬN}

Phẫu thuật nội soi điều trị thoát vị ben ở trẻ em với kim xuyển da tự chế là một phấu thuật an toàn, hiệu quả. Tính đớn giản của bộ dụng cụ có thể áp dụng phẫu thuật này tại các bệnh viện tuyến cơ sở.

\section{TÀI LIÊU THAM KHẢO}

1. Boocok G. R., Todd P. J. Inguinal hernias are common in preterm infants, Arch Dis Child, 1985, pp. 60-669.

2. Potts W. J., Riker W. L. and Lewis J. E. The treatment of inguinal hernia in infants and children. Ann Surg, 1950, 132 (3), 566-576.

3. Harrison M. R., Lee H., Albanese C. T., et al. Subcutaneous endoscopically assisted ligation (SEAL) of the internal ring for repair of inguinal 
hernias in children: a novel technique. J Pediatr Surg, 2005, 40 (7), 1177-1180.

4. Chen $Y$., Wang F., Zhong $H_{\text {., }}$ et al. A systematic review and meta-analysis concerning single-site laparoscopic percutaneous extraperitoneal closure for pediatric inguinal hernia and hydrocele.

5. Grosfeld, J. L., Minnick, K., Shedd, F., West, K. W., Rescorla, F. J., \& Vane, D. W. Inguinal hernia in children: Factors affecting recurrence in 62 cases. Journal of Pediatric Surgery, 1991, 26(3), 283-287

6. Michael W.L., Gauderer and Robert A. C.
Hernias of the inguinal region. Operative Pediatric Surgery, 2014, 489-509

7. Montupet P. and Esposito C. Laparoscopic treatment of congenital inguinal hernia in children. J Pediatr Surg, 1999, 34 (3), 420-423.

8. Takehara H., Ishibashi $H_{.}$Satoh $H_{.}$et al. Laparoscopic surgery for inguinal lesions of pediatric patients. In: Proceedings of the 7th World Congress of Endoscopic Surgery, 2000, 537-542

9. Grosfeld J.L., Engum S.A., and Tam P.K. Hernias in children. Operative Pediatric Surgery, 2012, 7th edition, 277-299.

\section{MộT Số YẾU Tố LIÊN QUAN ĐẾN CHẤP NHÂN TIÊM VẮC XIN PHÒNG COVID-19 DO VIỆT NAM SẢN XUẤT}

\section{TÓM TẮT}

Nghiên cứu mô tả cắt ngang trên 1020 người ở Việt Nam (VN) có độ tuổi từ 18 trở lên từ ngày $28 / 8$ đển $7 / 9 / 2021$. Muc tiêu nghiên cứu nhằm xác đinh tỷ lệ và một số yếu tố liên quan đến chấp nhận tiêm vắc xin phòng COVID-19 do VN. Kết quả: Có 86,37\% đối tượng nghiên cứu (ĐTNC) sẵn sàng tiêm vắc xin phòng COVID-19 do VN sản xuất. Các yếu tố liên quan đến tỉ lệ chấp nhận tiêm vắc xin phòng COVID-19 do VN sản xuất là nhóm tuổi 30-39 chấp nhân thấp hơn so với nhóm 18-29 là 0,62 lần $(p<0,05)$, nông thôn chấp nhân tiêm cao hơn thành phố 1,92 lấn $(p<0,05)$, giới tính nữ chấp nhân tiêm gấp 2,21 lần so với nam giới $(p<0,0010)$, đối tượng lao động tự do chấp nhận tiêm cao hơn công chức/viên chức là 1,79 lần $(p<0,05)$, tình trạng mắc bệnh mãn tính chấp nhân tiêm thấp hơn nhóm không mắc bênh là 0,39 lẩn $(p<0,001)$; người có tiền sứ dị ứng hoăc không biết mình có nguy cơ dị ứng hay không chấp nhận tiêm thấp hơn đối tượng không có tiền sử dị ứng 0,37 lần $(p<0,001)$ và 0,49 lần $(p<0,05)$. Kết luận: kết quả nghiên cứu cho thây tỷ lệ ĐTNC chấp nhận tiêm vắc xin do VN sản xuất là khá cao. Các yếu tố liên quan đến tỷ lệ chấp nhận tiêm vắc xin có ý nghĩa là vùng miền, giới tính, tình trang mắc bênh mãn tính và tiền sử dị ứng. Tứ khóa: Vắc xin phòng COVID-19; chấp nhận tiêm vắc xin; vắc xin phòng COVID-19 do Việt Nam sản xuất.

\section{SUMMARY}

RELEVANT FACTORS OF MADE-IN-VIETNAM COVID-19 VACCINATION ACCEPTANCE

A cross-sectional descriptive study was carried on

${ }^{1}$ Trường Đại học Y tế Công cộng

${ }^{2}$ Sở Nôi Vù-Tp Hà Nôi

Chịu trách nhiệm chính: Nguyễn Thị Hà

Email: nth16@huph.edu.vn

Ngày nhân bài: 22.10.2021

Ngày phản biên khoa hoc: 21.12.2021

Ngày duyệt bài: 30.12.2021
Nguyễn Thị Hà1, Ngô Văn Lăng1, Đặng Hùng Dũng ${ }^{2}$, Phạm Thị Yến Thư ${ }^{1}$

1020 Vietnamese people aged 18 or older from August 28 to September 7, 2021. The purpose of the study was to determine the rate and some factors related to the acceptance of vaccination against COVID-19 made in Vietnam. Results: $86.37 \%$ of the research subjects were willing to have vaccination against COVID-19 with Made-in-Vietnam vacine. Factors related to the acceptance rate of vaccination against COVID-19 with made-in-Vietnam vaccine can be listed as following: the acceptance rate of the group of 30-39 years olds was 0.62 times lower than that of the group of 18-29 years olds $(p<0.05)$, the acceptance rate of people in rural areas was 1.92 times higher than that of cities $(p<0.05)$, the acceptance rate of female research subjects was 2.21 times higher than that of males $(p<0.0010)$, the acceptance rate of self-employed workers was 1.79 times higher than civil servants $(p<0.05)$, chronic diseases made the acceptance rate of those with chronic diseases 0.39 times lower than that of healthy ones $(p<0.001)$; the acceptance rate of people with a history of allergies and those being doubtful of their allergies were $0.37(p<0.001)$ times and 0.49 times $(p<0.05)$ lower that of people without any history of allergies, respectively. Conclusion: The results of the study showed that the percentage of research subjects who accepted made-in-Vietname vaccinations was quite high. The sifnificant factors associated with vaccination acceptance rates were region, sex, chronic disease status, and allergy history.

Keywords: Covid-19 vaccine; vaccination acceptance; made-in-Vietnam vaccine against Covid-19.

\section{I. ĐẠT VẤN ĐỀ}

Dịch bệnh COVID-19 lần đầu tiên được báo cáo ở Vũ Hán-Trung Quốc vào ngày 31 tháng 12 năm 2019 [1]. Cho đến nay, dịch COVID-19 đã lan ra toàn cầu với số lượng người tử vong rất cao. Thống kê đến ngày $28 / 7 / 2021$, trên thế giới có 232.075.351 người mắc COVID-19 với tổng số ca tử vong là 4.752.988 [1]. Tại Viêt Nam, làn sóng thứ 4 của dịch COVID-19 kể từ tháng 